\title{
Teacher Pedagogical Choice
}

\author{
Peter Burridge
}

Additional information is available at the end of the chapter

http://dx.doi.org/10.5772/intechopen.73201

\begin{abstract}
This chapter examines teachers' pedagogical decisions and how routinization of practice can lead to the ineffective application of pedagogy that hinders student development and achievement. Identification of tacit knowledge that supports routinization can enable teachers to critique their teaching practice and identify pedagogies that are more appropriate for the students they teach. The work of Bourdieu and Giddens provides a sociological framework to analyse the influences on pedagogical decision-making. Evidence from a case study is used to illustrate how teacher professional habitus, motivation, ontological security, routinization and time and space interact to inhibit or enable expansion of teachers' knowledgeability and the frames of practice inform their choice and development of pedagogy.
\end{abstract}

Keywords: pedagogy, teacher decision-making, Bourdieu, Giddens, routinization

\section{Introduction}

It is recognised that teachers' make a difference to student learning [1]. The way they develop relationships with students, the classroom culture that is promoted, and the learning activities that are selected all influence students' motivation and engagement. These important pedagogic decisions are influenced by many factors, as classrooms are complex environments, with one adult teacher working with up to 30 young people of both sexes from a range of social and cultural backgrounds. This complexity increases, as the teacher's classroom is one of many within a school organisation that is managing to meet the needs of students, parents, teachers, administrators and government departments. However, the essence of the school is not the organisational structure or the buildings but the vast array of social relationships and interactions that occur in the normal durée of the school day. Understanding the social milieu found in schools provide insights into teachers' pedagogical choice. 
From John Hattie's meta-analysis studies we know that a teacher's influence on student achievement can be significant, but we also know that some actions are more effective than others [1]. Teachers need to be cognisant and targeted in the pedagogies they select to support student learning, something that is easily said but difficult to achieve due to the many influences on teachers' decision-making.

This chapter examines the influences on teachers' pedagogic choice, drawing on data collected from teachers and students over a 2 years study. Five factors that affect teachers' decision-making are presented, exploring how these factors interact to support or inhibit teachers to reflect on their teaching practice. The chapter concludes with a summary of the conditions that will support teachers to examine their practice and expand their knowledgeability about pedagogy.

\section{A sociological framework to understand pedagogical choice}

Bringing together the work of Pierre Bourdieu and Anthony Giddens provides a sociological framework that can be used to explore the social interactions that affect teachers' selection of pedagogy. Bourdieu's theories of social and cultural practice encompass the social aspects of teachers' pedagogical choice. His theories identify the role of habitus (our way of viewing and responding to the world) on our decisions and actions [2]. Habitus is the system of schemas of perception and discrimination people use to navigate their way through the social world and are developed through life experiences starting with the formative years of childhood. The combination of habitus and the social, cultural, economic and symbolic capital that we initially inherited from our parents moderates our actions and behaviour that Bourdieu refers collectively as practices [2]. People who inherit similar capital will tend to develop habitus that express similar tastes, values and behaviours and the inhabiting of similar social space. This social space is more than a class association. It "tends to function as a symbolic space, as space of lifestyle and status groups characterised by different lifestyles" [3]. These spaces can provide the individual with a range of support including, identity, security and power. These symbolic spaces are created, maintained and reproduced by the interaction of capital, habitus and practice. Consequently, there are a myriad of symbolic social spaces depending on the combination of habitus, capital and practices.

Student's habitus and capital will affect their readiness for school knowledge and will influence how students engage or resist school structures and the teaching practices being employed. Teacher's habitus will influence how they understand teaching practices and how they engage with students in their classrooms. Social groups will also form in the classroom as students identify with peers inhabiting similar social spaces. If the teacher does not develop a classroom culture that brings different social groups together, they may struggle for power and control in the classroom and undermine student learning.

Unravelling habitus and social spaces in the classroom can illuminate how students' background may affect interaction in the classroom and influence pedagogical decisions, but it does not take into account the range of external factors, such as school structures and educational 
policy. It does not link people and their actions to social structures. Giddens' theory of structuration does provide this framework as, Shilling summarises, "structuration theory does provide a new way of looking at the relationship between social interaction in schools and the reproduction of the major structural principles which characterise society" [4].

Giddens' theory attends to external factors that influence decisions, linking a person's action mediated by habitus with social structures. Social structures are rules and resources which can be both enabling and constricting on people's action, for example, religious groups, kinship groups or labour unions. These structures arise from social practices that are maintained over time. Giddens' theory identifies that the actions of people who make up social structures, such as schools will be influenced by these same structures and these same people will, in turn, influence the social structures through their actions [5]. For example, in Western countries, education and learning in schools are dominated by a scientific rationalist worldview. This is enabling to students when they use logical reasoning to gain a greater understanding of the world, but it is also constricting, as the dominance of scientific rationalism diminishes opportunities to use other approaches when faced with problems or understanding observed phenomena [6]. The dominance of this worldview is maintained by both the school structures, such as curriculum documents and through teachers' actions following these guidelines. This dominance will be maintained unless teachers' exert their agency and introduce other approaches and worldviews.

Time and space provide the cultural and historical context for the development of social structures. People's past actions have informed the current structure, and the longer these structures have been maintained, the more stable they become. This does not mean structures are unchanging as it is people's actions that determine the social structures and it is their actions that can create change. The difficulty is identifying the need for change. Social structures provide routines for people to deal with day-to-day activities of social life. These routines enable people to draw on tacit understanding to predict the actions of others, which at times seem automatic. Giddens' calls this routinization,

"The concept of routinization, as grounded in practical consciousness, is vital to the theory of structuration. Routine is integral both in continuity of the personality of the agent, as he or she moves along the paths of daily activities, and to the institutions of society, which are such only through their continued reproduction" [7].

Routinization provides predictability and feelings of being in control, which is the essence of ontological security. Feeling secure that regular events will occur lowers anxiety and frees the mind to be attentive for more unusual events. Ontological security increases the stability of social structures that strengthens with time, so for change to take place, people must become aware of their tacit understanding if they are to act purposefully that result in change.

To summarise, the work of Bourdieu enables identification of habitus and the power of social groups' influence within social structures. Giddens' work provides an understanding of the interaction of individuals with social structures, which lead to structural change or structural maintenance. Combined these two theories provide an insight into the social interaction at an individual, group and organisation level and uncover the range of factors that influence the pedagogical choices of secondary school teachers. 


\section{Influence on teachers practice and decision-making}

There are five significant factors that influence teachers' pedagogical decisions: habitus, teacher motivation, ontological security, routinization, and time and place. These factors are not always apparent to teachers resulting in unintended conditions that produce unintended consequences, which may inhibit or enhance student learning. Teachers' awareness of these factors can enable them to recognise the unintended conditions and make more effective pedagogical judgments.

An overview of each factor will be discussed, followed by how these factors inform pedagogical choice. Snippets from a case study will be threaded through the discussion to illustrate how the factors influence teachers' decisions. The case study examined changes to classroom practice by teachers at a secondary school located in Victoria, Australia that has been given the pseudonym Trimble Secondary College. This study was conducted over 2 years exploring teaching practices at the school and the factors influencing teacher's pedagogical choice. Data was collected through classroom observations, teacher interviews, interviews with the Principal and small group interviews with the students. Collecting data over the 2 years enabled the development of rapport and trust between the researcher and the participants leading to a richer understanding of the school community and classroom pedagogy. The school serviced a small rural community which was experiencing economic and social hardship. These conditions may have contributed to the difficulties at the school where teachers were struggling to engage students in learning and to developing positive classroom environments. To address the problem of student engagement and misbehaviour, they changed from teacher directed pedagogy to student centred pedagogy using cooperative learning as a foundation for building social connections and social capital in the classroom. The cooperative learning was focused on the concept of table groups, where students sat around tables in dedicated groups of four or five. Learning activities were designed to encourage discussion and supporting student understanding through a range of individual, partnered and group activities.

\subsection{Influence of professional habitus}

Professional habitus is an aspect of our habitus as detailed by Bourdieu, but it is the system of schemas and perceptions people use to understand their professional world. For teachers, these develop through educational experiences, teacher training programs, interaction with colleagues and professional development. As with other aspects of life, teachers participate in professional social spaces, forming social groups around shared understandings and teaching practices, such as being a science teacher or a primary school teacher. These social groups will tend to compete for influence within the social field of the school, exerting their power to have control or influence over decisions. In schools, this may be seen in science teachers lobbying for more resources for their subject in a school, or arguing that science must be taught in a particular way. Such group action reinforces professional habitus as group members confirm each other's schemas and perceptions. This group action will also develop routines, continuing with the science teacher example. The science teachers develop routines of science teaching that promote rationalist thinking and use of the scientific method. As the science teachers 
collaborate on the development of curriculum and assessing students learning, routines will strengthen and reinforce professional habitus. To critique established routines becomes challenging as unintended consequences can become hidden in the stability of the practice.

\section{Case snippet}

Moving away from teacher directed pedagogy to student centred cooperative learning pedagogy at Trimble Secondary College required teachers to critique their teaching routines that were well established and connected to their professional habitus.

I do not expect all the teachers to deal with it the same way I do because I have my style and they have their style, but I would hope that some staff would have a bit more empathy with the kids that cannot read and write and actually see that this kid cannot understand what I am saying and they are going to muck up. Kids will get their notoriety in other ways if they have to. (Sam, assistant principal).

There's a few of us that very much stick to the table group system, and there would be others that have their rooms set up in a different way, students not actually in the table groups. So it depends on the teacher and their approach. (Julie, classroom teacher).

Both Sam and Julie articulate how their professional habitus is informing their teaching. Sam draws on his humanist perspective of teaching taking into account students' background when interacting with them. Julie is a supporter of the cooperative learning and the table group approach being promoted by the school. Her work with colleagues and professional learning about cooperative teaching practices has guided her practice, while for other teachers their professional habitus has maintained more traditional teacher centred practices. Both examples highlight how acknowledgement of professional habitus is essential if teachers are going review their practice and select pedagogies that will be the most appropriate for the students they teach.

\subsection{Teacher motivation}

Schools are social institutions with policies, codes of behaviour both implicit and explicit that guide people's practice. This includes teachers, students, administration staff and parents. External factors such as economic conditions, and education department requirements impinge on peoples' action, as do internal factors such as how parents value education and teachers' professional habitus. These factors interact to create conditions of action, which influence a person's behaviour. How people interpret the conditions will inform their action and for teachers will influence their practice.

Examination and the evaluation of teaching practice require motivation. This impetus can come from both external and internal sources. Significant events such as a change in government policy, decline in student attendance or spiralling student anti-social behaviour are external factors that may compel teachers and school administration to examine classroom pedagogy [8].

Internal factors are drivers that are intrinsic to the teacher. For some, this may come from a drive to develop their personal practice for improved outcomes for all the students in their class. These teachers have become known as reflective practitioners, teachers who monitor 
and reflect on student behaviour and progress as an indicator of teaching practice [9]. For other teachers, intrinsic motivation may only occur when they have feelings of disequilibrium, a tension between what is happening in the classroom and their professional habitus [10]. These feelings of disequilibrium may lead the teacher to question their practice, as the events in the classroom have not progressed as normally expected.

\section{Case snippet}

The economic and social hardship facing the community Trimble Secondary College served was affecting students and their families. These circumstances flowed into the school with an increase in difficult behaviour and students not valuing education. Teachers were frustrated and looking for ways to improve student behaviour and classroom culture.

The kids can be uncooperative; the community has high unemployment, with quite a lot of poverty. Our students have habits of talking a lot of the time interrupting, not focusing, and they don't have those classroom skills. People can get frustrated. But it is getting better, it is about relationship building and teaching these skills, so kids can start learning. (Markus, campus principal).

I like to know where the students are at especially in maths. The other day I realised they 'do not know anything about 24 hour time'. So we had to go back over it. There are always things you assume they know that they do not. It is different with every group, you will start with an idea and the kids will take you where you need to go. (Julie, Year 8 classroom teacher).

Teachers' reflection on their students' capacities and understanding the influences on their learning provides insights into why some classroom practices may have been ineffective. Markus identifies that without the skills of active listening, turn taking and working in groups, students were unable to engage in classroom activities. He recognised that teaching personal and social skills required in the classroom must be attended to along with content and concepts. Likewise, Julie acknowledged that students' background knowledge in maths varied and without foundation knowledge, she was unable to introduce more complex ideas to students. Both teachers were motivated to support students' learning and were able to identify external and internal factors that are impinging on their students. This realisation informed their choice of pedagogy and classroom practice.

Whether external or internal or a combination, these factors drive teachers' motivation to ask questions about pedagogical choice. How this review occurs and the response to the questions asked will be influenced by the following three factors of ontological security, routinization and time and space.

\subsection{Ontological security}

Personal feelings of safety come from a sense of predictability and routine, known as ontological security, where people have an awareness of their personal presence in the world, of being real with a sense of continuity through space and time as one interacts with others in day-to-day activities [11]. Within schools, feelings of ontological security are enhanced by the institutional structures, including timetables, school traditions and rules which provide the school community with high levels of predictability. 
Ontological security develops through lived experience as people interact with the world around them. Predictable routines are recognised such as sunrise and sunset, the human response to a smile or the trust a child has in their parents. These routines and responses not only confirm one's own and other people's reality and identity but also provide a capacity to predict the responses of others. It is this ability to predict possible outcomes either tacitly or consciously which manages anxiety. Being able to manage anxiety provides feelings of control and ontological security.

Maintenance of ontological security is one of the motivating forces for abiding by social practices and the reproduction of social structures. Tacitly knowing how people will respond to a particular action builds trust and a sense of safety. Feelings of ontological security govern our sense of control and ability to evaluate potential outcomes of action. Feelings of insecurity come from threats to our identity, or the capacity to cope with the demands life may place upon an individual [12]. It is possible that for many teachers reviewing and exploring different classroom practices is seen as a threat to their professional identity and professional habitus producing high levels of anxiety. This level of anxiety may result in avoidance and a teacher not evaluating their teaching practice. For other teachers with a stronger ontological security may see reviewing teaching practice as an exciting and challenging prospect which will further their understanding [13].

\title{
Case snippet
}

\begin{abstract}
It is a real challenge for some people to work with the table groups, having students facing each other and working together. If you don't use cooperative learning, it won't work, and individuals will distract each other. We need it to be a whole school approach, to build a social connection so when a student comes into a class they don't feel alone, 'they have a group to work with'. Some teachers have resisted they, say but 'this works for me so why change'. The professional learning teams are helping with people sharing ideas and successful approaches (Ken, Year 8 classroom teacher).
\end{abstract}

As seen in Ken's observation the ability for people to manage anxiety is the key to taking action and is connected to ontological security. Those people with strong levels of ontological security feel less threatened by unknown outcomes of their actions and are more able to take action [14]. In the case of pedagogical choice, taking action involves evaluation of current teaching practices with the aim to develop a pedagogy that will better support student learning. In the case study, the school has established professional learning teams to provide support for the development of teachers' ontological security. Sharing experiences of classroom teaching provides a forum to discuss different approaches. With examples of successful strategies, teachers who feel anxious may be encouraged by the positive outcomes of others to take action.

\subsection{Routinization}

Routinization is bound with the tacit knowledge that is primarily carried in the practical consciousness and "consists of all things which actors know tacitly about how to 'go on' in the contexts of social life" [15]. People are able to go about their lives without having to closely examine every aspect of life, as tacit understanding from the practical consciousness enables 
one to predict the actions of others in various situations. This is in contrast to when people use their discursive consciousness, which is the level of consciousness that deals with new or unusual situations. When drawing on our discursive consciousness we are thinking about the events being experienced and the action we should take. Unlike the action resulting from the practical consciousness we are able to justify and articulate our actions. With both the practical and discursive consciousness, agents are aware of their actions. This is in contrast to the unconscious, which is not easily defined, but can be considered as those aspects that we are unaware and are readily access through the practical consciousness.

Routinization occurs when social routines become imbedded overtime into the practical consciousness and are illustrated by our automatic responses to events such as a greeting or cultural ritual. The predictability of these situations strengthens our feelings of ontological security. Social institutions such as schools have many routines that become routinized, for example, timetabled classes, holiday periods, codes of behaviour and school rules. These routines and norms create high levels predictability and corresponding ontological security to a point where people have a shared tacit knowledge or framework of behaviour. Within schools this framework is robust and fragile, robust due to the reliability of the framework proven over time through teachers' and students' experiences, but fragile when an unexpected reaction occurs creating feelings of anxiety and disequilibrium.

\section{Case snippet}

Schools have many routines that can be supportive to student learning as students can predict what lays ahead providing feelings of security. Some routines can also be inhibiting such as inflexible discipline policies that raise students' levels of anxiety or increase levels of conflict.

We start the day with homeroom, Miss Lee says good morning and reads the bulletin and then you get into first period. We have her every morning, as she is our homeroom teacher. She knows all of us. Like, she can look at you and read you like a book I reckon; well she can do that with me anyway (Jessie, Year 7 student).

Jessie describes an effective routine of how the school day commences giving the students time to settle and find out about the day ahead. This has also assisted Miss Lee to know her students well. This relationship supports learning as Jessie identifies that Miss Lee can 'read her like a book', being able to determine if she is having difficulty or needs extra help.

Routinization as described enhances the function of the school by supporting the communication and understanding between teachers and students. It can also be inhibiting when routines stop people examining the performance of the school. Teachers may become comfortable with the routines and consciously or unconsciously support ineffective routines as part of their shared framework, rather than evaluate and look at the possible change to teaching practices. With routinization being linked to ontological security awareness of how to support teachers to manage levels of anxiety is important if routines are to be critiqued and when required, changed [16]. 


\subsection{Time and space}

Time and space have multiple influences on schools as institutions. Spaces in schools are present in physical, social and communicative forms. Physical spaces are the classrooms, offices, halls, online space and other resources where people can come together. Social spaces are more symbolic and include those connected to peoples' habitus. Communicative spaces can cross the boundaries where people come to share ideas and experiences. These communicative spaces can be selective such as the classroom and the staff room involving particular people or more open such as a community forum where teachers, students, parents and others may come to share ideas.

Time places actions into a temporal context where past actions will influence current settings. Routines become routinized through persistence over time. Time is also a resource in schools with groups competing for time to be allocated to their activities. So time has two influences on pedagogical decisions. First, the length of time current practices has been in place will determine the stability of the practice, and second, more time will be required to critique and change highly stable practices.

To examine and reflect on current routines and pedagogies teachers need 'physical time' away from the demands of classroom teaching to reflect on current teaching practices. Emotional and cognitive space is required to be able to 'step outside' school routines and critically examine the effectiveness of pedagogy being employed. Without both time and space, the tacit knowledge of school structures and routines have the potential to overshadow critical analysis, leaving ineffective pedagogy unidentified and unchanged.

\section{Case snippet}

At Trimble Secondary College they recognised the importance of critical reflection. Identifying that the process of review needs both time and a communicative space where teachers can discuss and share ideas.

What we really wanted to get going was professional learning teams to build that culture of sharing. On Monday nights we meet in Professional Learning Teams that are a mix of curriculum backgrounds and people focus on pedagogy. They research an approach and trial it in their classroom, like integrated projects or thinking tools. The groups then report back to each other later in the year with examples from their classroom, student's work, and videos of lessons. It is great, and there has been some fantastic work done, with people taking on new ideas because they see that it works. (Trevor, classroom teacher and program coordinator).

This use of meeting time is unusual in Australian schools, with teachers meeting in mixed groups not focusing on subject content or student behaviour, but on pedagogy. The diverse subject backgrounds of teachers bring different teaching knowledge and professional habitus to the team discussion. For example science, English and physical education teachers will have different classroom practices. Sharing these practices provides a starting point for rich discussion about teaching and learning. As Trevor described, the teachers' in their professional learning teams focus on 
pedagogy. They choose an approach they have found effective in one situation and research how it might apply to different subject areas. Being provided time and space for these discussions promotes reflection and critique, which encourage teachers to trial different approaches.

\section{Supporting teachers to evaluate pedagogy}

The discussion so far, supported by the work of Bourdieu and Giddens has identified the stability of classroom practices. Teachers tend to maintain their practice from 1 year to the next and from one class to the next, unaware of the unintended consequences of their actions and institutional routines. Supporting the evaluation of their pedagogy is essential if teachers are to become reflective practitioners.

It is the interaction of the five factors described; habitus, teacher motivation, ontological security, routinization, and time and place that either promote or inhibit teachers' to reflectively evaluate and select approaches that will be most useful for their students. For example, a teacher may be motivated to change teaching practice to more effectively engage his or her students in their learning. However, if the teacher is unaware of routinization or is ontologically insecure, it is unlikely that the changes to pedagogy required will be identified. The capacity of teachers to critically evaluate the pedagogy they use in their classrooms is linked to their knowledgeability.

Giddens suggests that knowledgeability is a person's understanding of the rules and norms that make up social structures. In the case of teachers this will be both the rules and norms of the community and also at a professional level the rules and norms of teaching and the school in which they work. In schools, many of these will be implicit and only understood through experience and interaction with others. A teacher, student or parents' knowledgeability about a school will be their understanding of the conditions in the school and how these influences the way people act. For example, if a school has a long history or being involved in the arts, students' involvement in the annual school drama production is highly valued. Awareness of this school norm would help a new teacher to the school understand the enthusiasm of student participation in the performing arts. In contrast teachers can be puzzled and frustrated due to a lack of knowledge about conditions in the school. For example, if the local community the school serves is experiencing economic and social hardship students may be dealing with many stresses in their home life that is reflected in off task behaviour in the classroom. If teachers are unaware of these situation actions in class that would normally support student engagement may prove ineffective.

It is the difference between what is known and not known that can lead to unintended consequences of action by teachers. Expanding teachers' knowledgeability occurs when a person becomes aware of the conditions that lead to unintended consequences. This means that expanding teachers' knowledgeability has the potential to uncover routines supported by the tacit knowledge that undermined student achievement.

Burridge, Hooley and Neil have proposed that knowledgeability is linked to the concept, 'frames of practice'. These are the approaches and procedures that teachers use to build relationships and a classroom culture [17]. Teachers' frames of practice develop through experience, reflection 
and study where novice teachers will have less complex and established frames compared to an experienced teacher. As frames of practice become established and stable they become part of the tacit knowledge of the practical conscious. Experienced teachers will draw on these reflexively to manage their classrooms. This allows the discursive conscious to be attentive to students learning needs and unexpected or unusual happenings in the classroom. As teachers understanding of teaching grows so does the complexity of their frames of practice and with more complex frames, teachers become more competent to deal with new problems or situations. Figure 1 illustrates this growth of new frames of practice, with more frames being developed and becoming stable in the practical consciousness as the teacher's understanding grows. These new frames are developed through reflection on teaching experience identifying previously unacknowledged conditions that led to unintended consequences of action.

In the centre of Figure $\mathbf{1}$ are examples of frames of practice that a teacher may draw on when managing a class. The frames are connected as different frames interacted to inform a

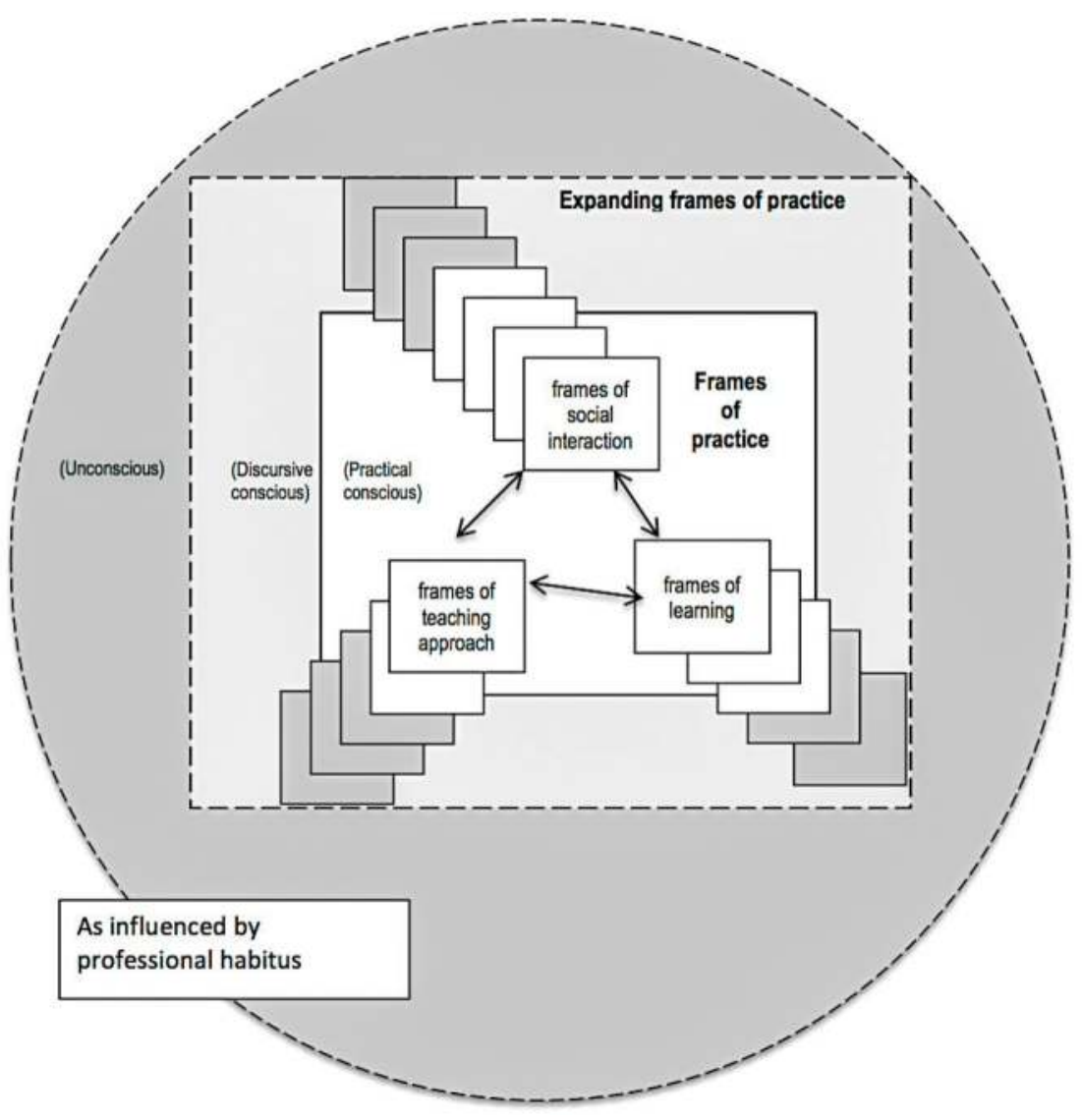

Figure 1. Development of frames of practice. 
teacher's action. This occurs reflexively through the practical consciousness. New frames start to develop through the awareness of the discursive consciousness identifying the conditions leading to unintended consequences. This new awareness can lead to new approaches and procedures being used that over time can become stable and added to the established frames within the practical consciousness. In this way teachers build their tacit knowledge of teaching practice, and their capacity to reflexively monitor and manage classrooms.

Problems occur when these established frames of practice are not attending to the needs of students, but the teacher unknowingly relies on this practice. This may come about through a change in circumstances or the influence of professional habitus clouding pedagogic judgement. Whichever the reason, it highlights the need to regularly examine practices to reveal unacknowledged conditions that may be leading to unintended consequences.

Collaborative discussions with peers as illustrated by Trimble Secondary College teachers' professional learning teams are an example of how practices can be examined. When teachers openly reflect on their teaching practices, describing and critiquing specific actions, unacknowledged conditions that lead to unintended consequences can be uncovered.

\title{
Case snippet
}

In Year 8, English classes studying how to write a biography, involved students researching and writing about a famous Australian. The level of student engagement was quite low, with only half the students completing the assignment. Although the approach was ineffective it had been the standard approach for years. Through discussions with colleagues, the teachers reviewed their practice and came to the conclusion that stories of famous Australians did not connect with the students' lives and their local community. This observation led to a change of approach by asking students to write a biography about a significant adult in their lives, which they would then present to family and community members.

\begin{abstract}
They learnt about skinny and fat questions and eventually, they had to find someone to interview and taped their interview and wrote their books. Then we had a night where they could bring their families and the person that they wrote about to a presentation night. The books were great, and I was really proud of them (the students). The kids had to get up in front of everyone. We had about 70 people at each night which is a better proportion than parent teacher interview nights, because their kid was going to present something. (Tony year 7 teacher).
\end{abstract}

Connecting the curriculum directly to students lives combined with the authentic assessment of presenting the biography to an audience required a change in pedagogy. This only occurred when teachers identified the unacknowledged conditions of action of an assessment task that lack relevance to the students. The change to the task then altered the skills being taught and the pedagogy being used with a corresponding change in student engagement and learning.

For discussions such as the one described, that critiqued teaching practice, to occur, a trust environment must be present. Habermas' refers to this environment of trust as the 'public sphere' [18]. Within the public sphere, all opinions are given equal merit, and the discussion is an inclusive process with the goal of purposeful action that Habermas identifies as communicative action [19]. In communicative action participants are not primarily oriented to their own individual successes; they pursue their individual goals under the condition that they 
can harmonise their plans of action on the basis of a common situation and definitions [20]. In essence, the focus of communicative action is towards understanding, learning and enlightenment [21]. Strategic action, in contrast, is where a group is focused on a predetermine outcome that maintains their position or power with in a setting. Such action will undermine the focus on understanding and whether done openly or covertly, will compromise the reflectively discursive process, summarised in Figure 2.

The interaction of the elements identified in this process supports teachers to take purposeful action. Development of public sphere for reflective discussions is the essential factor for the process to occur. Without open conversations about teaching practice unacknowledged conditions that lead to unintended consequences will not be identified and effective change to pedagogy unlikely.

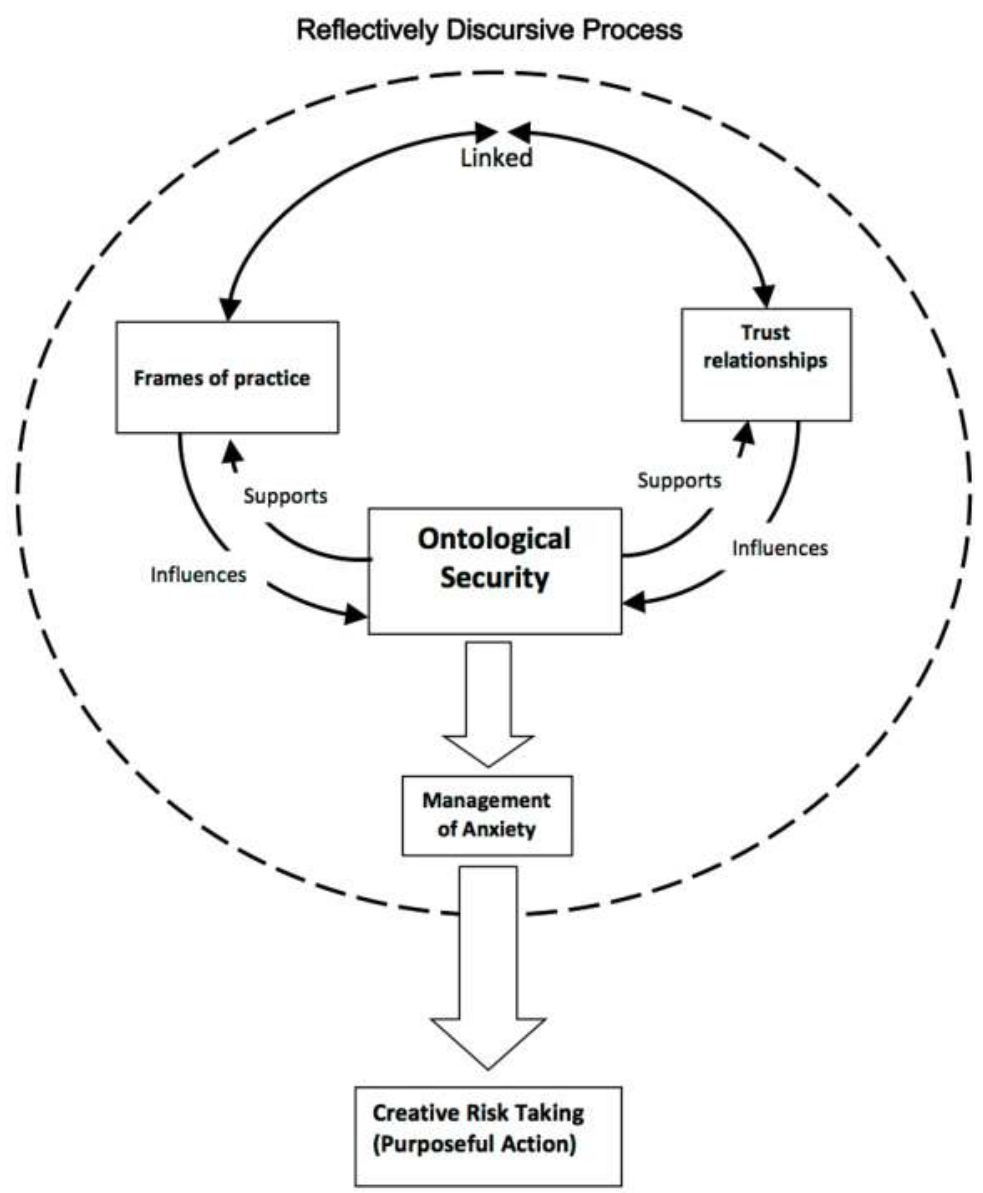

Figure 2. The reflective discursive process. 
The public sphere and development of trust will require an acknowledgement of different professional habitus and frames of practice. Supporting teachers to share their perspectives on teaching and learning will lead to richer reflective discussions uncovering the unintended consequences of practice, with an expansion of knowledgeability and frames of practice. This deeper understanding of teaching leads to more complex frames of practice that strengthens ontological security. The strength comes from teachers being able to manage anxiety, as anxiety is linked to the unknown outcome of choice [9]. Where there is a choice there is always the risk of choosing a course of action that will not result in the desired outcome. With more complex frames of practice, teachers are more able to see the range of possible outcomes, with an associated confidence in choosing a positive course of action.

Even with a more sophisticated understanding of teaching practice and awareness of possible outcomes, change will only occur when teachers take action. This may seem obvious, but routinization, a desire to maintain ontological security and the influence of professional habitus supporting personal identity can be significant barriers to change. As discussed, the rules and norms of social structures although created by people also influence people's actions. In schools, as with all social structures, norms and rules exist because teachers have maintained the practices over time. This duality is the both a strength of social structures and a weakness. It is strong through providing a sense of security and weak when ineffective practices are perpetuated.

Because of the duality within social structures it is difficult for the action of one person to have an effect on the institution's structures or practices. Social structures develop through people reproducing the practice over time, leading to routinization. If the actions of many people are required to reproduce the practices the action of one person can be easily absorbed without a change to structures or practices.

This is seen in schools where ontologically secure teachers may transform the learning of the students in their classrooms, but other classrooms remain unaffected. For ontological secure teachers to have an effect on the structure of schools, they must assemble the social and cultural capital required for other teachers to view their actions as legitimate. If the actions are seen as legitimate, there is a greater likelihood of widespread change, but this will not occur without teachers involved in the process developing the levels of ontological security required to take creative risks for change.

\section{Case snippet}

No, personally I thought people wouldn't be game enough to make the change, it doesn't sound like a big change, but for a secondary school it was... (Trevor, classroom teacher and program coordinator).

Mind you, the way we were operating at one stage here, on this campus; you probably wouldn't have wanted your kid to come to the school... Things have changed that much... if the kids have a disagreement, you can sort things out as people rather than just power. (Ken, Year 8 classroom teacher).

To change every classroom, every teacher had to accept it; it was no good if one person didn't, every classroom had to teach in that way. We knew that it meant a change in pedagogy... I really thought people would say, "no, this is too big", some said that, others were nervous but we went ahead anyway, and it's the best thing we ever did. 
There was no one particular person leading it and that was the other powerful thing. It was like a team. There was Jimmy Hills and myself and another couple pretty interested in this idea, but no one was really running it. Each week we would come along discuss and report back and it gathered its own momentum. (Trevor, classroom teacher and program coordinator).

Ken and Trevor's comments highlight the stability of schools and the difficulty of change. Ken described the student behaviour and the difficulties at the school as serious that provided a strong motivation for change. Even in this situation, teachers were hesitant with fear of the unknown, high levels of anxiety were present that the situation might become more difficult. Trevor's reflections on moving to the table group approach in classrooms and cooperative learning was a significant change for teachers. It challenged not only the current structures of the school, but also the teachers' ontological security and professional habitus.

A number of ontologically secure teachers led discussions about pedagogy that was the catalyst to reflect on current practices. The teachers came together to discuss approaches with all opinions being valued. It was this reflection in the trust environment of the public sphere that led to an expansion of teachers understanding and frames of practice. Only then were teachers able to take creative risks and implement cooperative learning pedagogy.

Such action highlights the teacher as the agent of pedagogical change, and it is the teachers' ability to, "rethink their social relationships and pedagogical practices within and outside of school...questioning and shedding previously cherished values and beliefs" [22], which provides the conditions to change pedagogy. It is this type of critical questioning that occurs through reflectively discursive activities which expand teacher frames of practice, developing the ontological security required for teachers to take purposeful action around pedagogy.

\section{Conclusion}

Teachers make a difference to student learning when they choose pedagogies that meet the needs of the students they teach. Indications that these choices have been effective will be seen in the students' level of engagement with the learning activities, development of the students understanding of the concepts taught and their ability to apply these concepts to settings beyond the classroom. However, too often teachers become reliant on routine and are drawn into a reproduction of teaching practice rather than an evolution of their teaching practice that is responsive to the students being taught [9].

To support teachers in making pedagogic decisions that are appropriate for their students, a number of conditions need to be met. First, space and time are required. Space refers to a cognitive environment different to the norms of their practice. Gathering together people from across teaching disciplines provides such an environment, as teachers from different subject areas bring a range of perspectives to evaluate pedagogies being used.

Time is needed for the development of trust which results in deeper reflective discussions. In the trust environment of the public sphere, all opinions are given equal merit and the critique 
of practice is focused on achieving a more complex understanding of student learning. For many groups of teachers this will take time and will require teachers to meet regularly in multi-discipline groups to discuss teaching practice and their pedagogical choices. As trust develops teachers will be able to openly acknowledge their professional habitus, with collaborative discussions leading to the identification of unintended consequences of their current practices leading to an expansion of their knowledgeability.

With an expansion of knowledgeability comes an increase in teachers frames of practice and more complex understanding of the school community, students and their learning. This deeper understanding of the school context and students learning can identify changes that need to be made to pedagogy. Determining the need for change is only the beginning. Taking action requires teachers to have levels of ontological security that enables them to overcome routinization to enact the change. Teachers who are ontologically secure are more able to manage anxiety enabling them to move out of the social field of professional habitus and the established routines of practices and to take purposeful action to modify or discard teaching practices identified as not supporting student learning, demonstrating reflexivity.

It appears that professional habitus and ontological security are very strong influences on pedagogical choice, with both elements supported by the established routines of secondary school structures. With Giddens' theory of structuration highlighting the duality of structure and Bourdieu's theories of social and cultural practices emphasising the importance and influence of social identity, changes to pedagogy will not involve a simple intervention from education departments or direction from school principals. To sustain pedagogical change within secondary school classrooms, the issue of teacher ontological security and the influence of professional habitus must be addressed. This requires a change to the power relationships within schools to enable teachers to participate in interdisciplinary reflectively discursive inquiries, where the school principal and administration support the deliberations. This requirement is in contrast to the current neo-liberal approach to government and the economy which has driven the commodification and marketization of education. Education departments and school principals must move away from developing a culture of performativity which privileges academic test scores to a culture which promotes teacher collaboration through the goal of nurturing and developing young people to become engaged members of society.

\section{Author details}

Peter Burridge

Address all correspondence to: peter.burridge@vu.edu.au

Victoria University, Melbourne, Australia 


\section{References}

[1] Hattie J. Visible Learning: A Synthesis of over 800 Meta-Analysis Relating to Achievement. New York: Routledge; 2009

[2] Bourdieu P. Distinction: A Social Critique of the Judgment of Taste (R. Nice. Trans.). London: Routledge; 1984

[3] Bourduie P. Social space and symbolic power. Sociological Theory. 1989;7(1):20

[4] Giddens A. Modernity and Self-Identity: Self and Society in the Late Modern Age. California: Stanford University Press; 1992. p. 84

[5] Giddens A. The Constitution of Society: Outline of Structuration Theory. Berkeley and Los Angeles: University of California Press; 1984

[6] Arends J. The role of rationality in transformative education. Journal of Transformative Education. 2014;12940:356-367

[7] Giddens A. The Constitution of Society: Outline of Structuration Theory. Berkeley and Los Angeles: University of California Press; 1984. p. 60

[8] Lampel J, Shamsie J, Shapira Z. Experiencing the improbable: Rare events and organisation learning. Organisation Science. 2009;20(5):835-845

[9] Sachs J. The Activitist Teaching Profession. Buckingham: Open University Press; 2003

[10] Festinger LA. A Theory of Cognitive Dissonance. Stanford, CA: Stanford University Press; 1957

[11] Laing RD. The Divided Self: An Existential Study in Sanity and Madness. New York: Routledge; 1960

[12] Spitzer SP. Ontological insecurity and reflective processes. Journal of Phenomenological Psychology. 1978;8(2):203-217

[13] Kirby S. Dimensions and meanings of anxiety. Existential Analysis: Journal of the Society for Existential Analysis. 2004;15(1):73-86

[14] Prince G, Is RD. Laing's concept of ontological insecurity applicable beyond schizophrenic experience? Existential Analysis. 2005;16(2):284-299

[15] Giddens A. The Constitution of Society: Outline of Structuration Theory. Berkeley and Los Angeles: University of California Press; 1984. p. xxiii

[16] Macintyre Latta MM, Kim JH. Narrative inquiry invites professional development: Educators claim the creative space of praxis. Journal of Educational Research. 2009; 103(2):137-148 
[17] Burridge P, Hooley N, Neal G. Creating frames of practice for teacher education. AsiaPacific Journal of Teacher Education. 2016;44(2):156-171

[18] Habermas J. The Structural Transformation of the Public Sphere: An Inquiry into a Category of Bourgeois Society. Cambridge: Polity Press; 1992

[19] Edgar A. Habermas: The Key Concepts. London: Routledge; 2006. p. 21

[20] Outhwaite W. The Habermas Reader. Cambridge, England: Polity Press; 1996. p. 161

[21] Godin P, Davies J, Heyman B, Reynolds L, Simpson A, Floyd M. Opening communicative space: A Habermasian understanding of user-led participatory research project. The Journal of Forensic Psychiatry \& Psychology. 2007;18(4):452-469

[22] Giles C, Hargreaves A. The sustainability of innovative schools as learning organizations and professional learning communities during standardized reform. Educational Administration Quarterly. 2006;42(1):124-156 